\title{
Research on Waterway Regulation of Fluctuating Backwater Zone of Ankang Hydro-junction
}

\author{
Wanli LIU1, a , Xiaofei LIU1, Kejun PING ${ }^{1}$, Pengfei LIU ${ }^{1}$, Ying LU², Fei HAN², \\ ${ }^{1}$ Key Laboratory of Engineering Sediment of Ministry of Communications, Tianjin Research \\ Institute for Water Transport Engineering, Tianjin 300456, China
}

\author{
atjtgliuwanli@163.com \\ ${ }^{2}$ Changjiang Waterway Bureau, Wuhan 430010, China
}

\begin{abstract}
Keywords: fluctuating backwater zone; principle of waterway regulation; mathematical river modeling; waterway regulation works

Abstract. The navigation water flow conditions in fluctuating backwater zone of Ankang hydrojunction not only are influenced by daily regulation flow of Shiquan hydro-junction upstream, but also are influenced by reservoir operation of lower Ankang hydro-junction. The flow in fluctuating backwater zone is characterized not only with the characteristics of mountainous river, but also with the characteristics of reservoir area. At the same time, the reach is a continuous rush curve reach with rapid flows. This paper presents a study of two-dimensional modeling for fluctuating backwater zone of Ankang Hydro-junction, following a sustained research program. A depth-averaged twodimensional mathematical model is established under the orthogonal curvilinear body-fitted coordinate system with staggered grid. The governing equations of flow are discretized with the finite volume method. The computed water level, velocity are verified by field data in the fluctuating backwater zone of Ankang Hydro-junction. It is shown that the flow field in fluctuating backwater zone can be simulated reasonably well. According to the characters of the fluvial process and navigation-obstruction, the regulation method is presented. Based on the aforementioned regulation method, Variations of water level, surface slope and flow velocity, caused by the regulation works in fluctuating backwater zone of Ankang Hydro-junction are analyzed. And finally, the reasonable regulation works are proposed.
\end{abstract}

\section{Introduction}

The fluctuating backwater zone of Ankang Hydro-junction located between the Xuanwo which is 58 $\mathrm{km}$ far from the upstream Shiquan Hydro-junction and Hanwang City. The section is $11 \mathrm{~km}$ and has 6 rapid shoals. There are a lot of reefs, bed rocks, narrow and rapid shoals with rapids, and there are also sand and cobble shoals. This reach is influenced by both the daily regulation flow of the upstream Shiquan Hydro-junction and the reservoir operation of the downstream Ankang Hydrojunction. The fluctuation amplitude of the water level is large. When the water level is low, the rapid shoals are exposed, which obstructs navigation seriously and needs regulation and maintenance. At the same time, this reach is continuous meandering segment with rapids, which is difficult for research. This article adopts technological method of two-dimensional plane flow mathematical model to research the regulation project scheme for dangers shoals of the reach of fluctuating backwater zone (as shown in Fig.1).

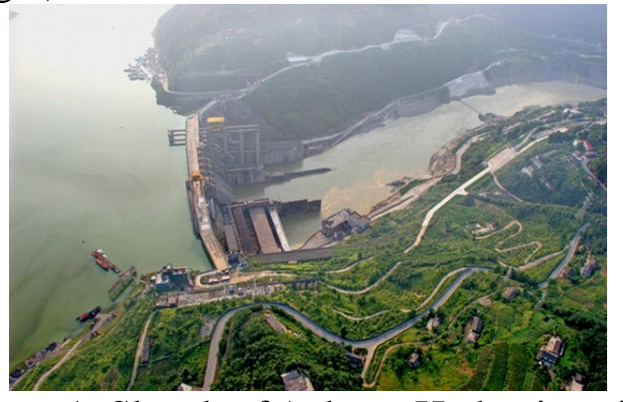

Figure 1. Sketch of Ankang Hydro-junction 
The regulation goal of this reach is to be reaching Grade VI. The waterway dimension is 1.2 $\mathrm{m} \times 22 \mathrm{~m} \times 180 \mathrm{~m}$ (navigation depth $\times$ navigation width $\times$ curvature radius). The surface flow velocity is less than $2.5 \mathrm{~m} / \mathrm{s}$ and the slope is less than $3.0 \%$.

\section{River Course Profiles and Natural Characteristics of Navigation-obstructing Shoals}

The reach of Ankang Reservoir can be classified into fluctuating backwater segment and perennial backwater segment. The fluctuating backwater zone is located between Xuanwo in downstream of Shiquan Hydro-junctionand Hanwang City. The length is $11 \mathrm{~km}$ (as shown in Fig.2). The reach between Hangwang City and the Ankang Dam is perennial backwater segment. When the water level before dam of Ankang Hydro-junction decreases to $310 \mathrm{~m}$, the fluctuating backwater segment will return to natural river status. There are 6 navigation-obstructing shoal in the reach. They are respectively Boguo Shoal, Yanzi Shoal, Yanzi Stone Shoal, Tongtong Shoal, Tongtong Bay Shoal, and Hanwangcheng Shoal (as shown in Fig.2)

The navigation water flow condition of the fluctuating backwater segment is influenced by both the daily regulation flow of the upstream Shiquan Power Station and the reservoir operation of the downstream Ankang Power Station; the water flow has characteristics of both rapid shoals of the mountain river and the river course flow of reservoir region. When the river course is influenced by backwater of Ankang Hydro-junction, the rapid shoals of the river course are submerged, the water flow is gentle and the water surface is open, which are characteristics of waterway of reservoir region; when the water course is not influenced by the regulation of Ankang Hydro-junction, the waterway becomes narrow, the slope flow velocity increases, the rapid shoals are exposed when the water level is low, the navigation channel is changeable, the water depth is seriously insufficient and the slope flow velocity of partial shoal segment is high. Due to the waterway without being regulated, the navigation condition of this reach in dry season is very poor.

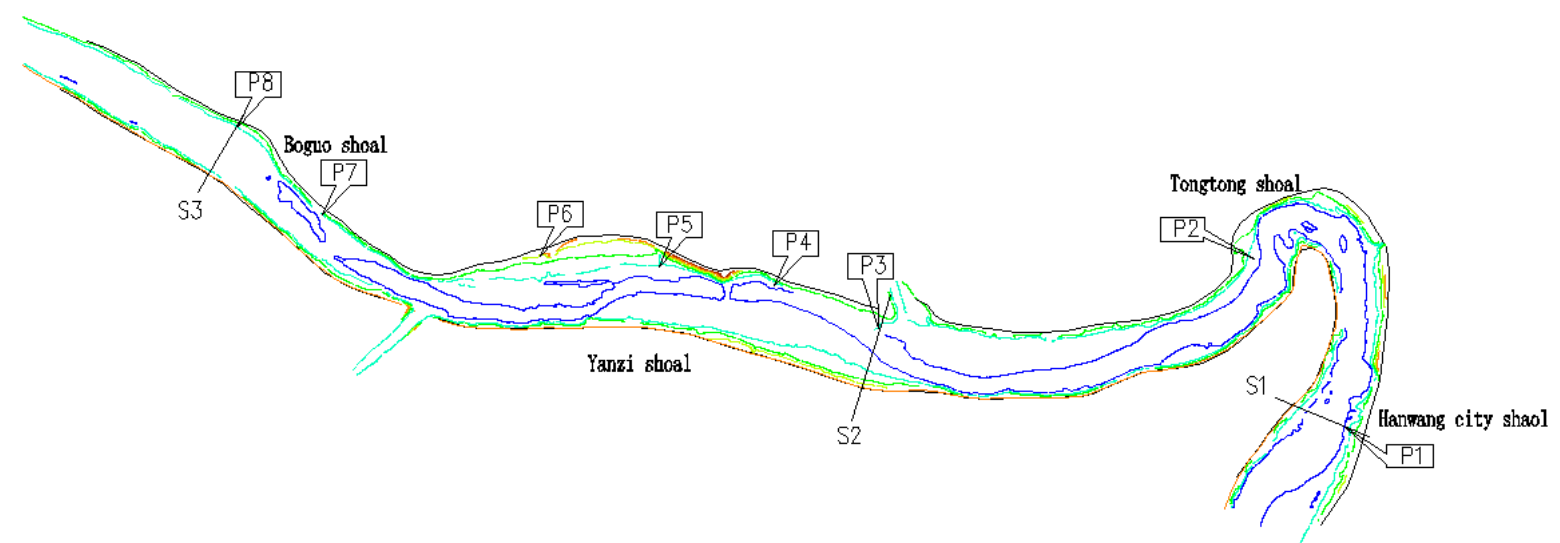

Figure 2. Sketch of Fluctuating Backwater Zone of Ankang Hydro-junction

\section{Selection of the Computation Domain and Generation of the Orthogonal Curvilinear Grid}

Under body-fitted coordinates, the two-dimensional plane flow mathematical model is controlled by the following equations (S. V., 1980; Li, 1986; Dou, 1987; Cheng, 1988; Zhang et al., 1989; Xie, 1998; Pan, 1999; Liu, 2003; Liu, 2004):

According to the river characteristics in fluctuating backwater zone of Ankang Hydro-junction, a depth-averaged two-dimensional mathematical model is established under the orthogonal curvilinear body-fitted coordinate system with staggered grid. The governing equations of flow are discretized with the finite volume method.

The computation domain is the reach from Boguo Shoal to Hanwang City Shoal. The computation scope is about $7.5 \mathrm{~km}$ (as shown in Fig.2). In the computation domain, set $61 \times 251$ grid nodes. After orthogonal transformation, the orthogonal curvilinear grid is got (as shown in Fig.3). The boundary line is the boundary of original river course. The domain under the new coordinate 
system $(\xi, \eta)$ corresponding to the orthogonal curvilinear grid is $61 \times 251$ rectangular grids. The length of the grid is $20-40 \mathrm{~m}$, and the width is $3-6 \mathrm{~m}$.

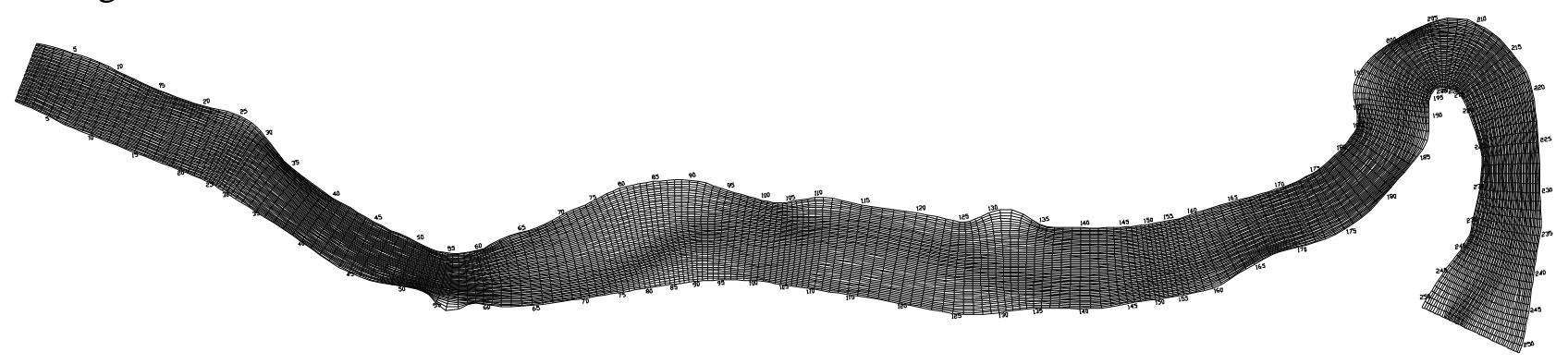

Figure 3. Sketch of Computational Mesh

\section{Computation of Regulation Works and Analysis of Its Effect Model}

\section{Arrangement of the Regulation Works.}

The design discharge and regulation discharge are respectively $74 \mathrm{~m}^{3} / \mathrm{s}$ and $150 \mathrm{~m}^{3} / \mathrm{s}$.

Implementing channel-dredging and mouth-cutting project at the place where the water depth in the navigation channel is insufficient. The curvature radius of the navigation channel in Tongtong Shoal-Tongtong Bay is designed to be 180m; Six spur dikes are arranged in the downstream reach. Four submerged dikes are arranged at the deep channel of the downstream of Tongtong Bay. The regulation line width is $70 \mathrm{~m}$.

\section{Computation and Analysis of the Regulation Works Effect.}

\section{Variations of the water depth and slope.}

The lowest water depth in the navigation channel of the whole reach is in Yanzi Stone Shoal, the value of which is $1.22 \mathrm{~m}$ (under the design discharge). The whole reach has achieved the requirement of $1.20 \mathrm{~m}$ navigation water depth.

Under discharge of each class, all the slopes in the navigation channel of the whole reach are less than 3.0\%o; among them, the maximum slope is at Yanzi Stone Shoal, and the value is $2.94 \%$ (under the design discharge); All the slopes of the whole reach have achieved the navigation requirements.

\section{Variations of the flow velocity.}

From the computation results (as shown in Fig.4), we can know that: (1) the water flow regime of the whole reach is smooth, and the transverse flow in the navigation channel is very small; and (2) The flow velocities of each shoals under discharge of each class all decrease to a certain extent, and the maximum values of surface flow velocities of each shoal are all below $2.5 \mathrm{~m} / \mathrm{s}$.

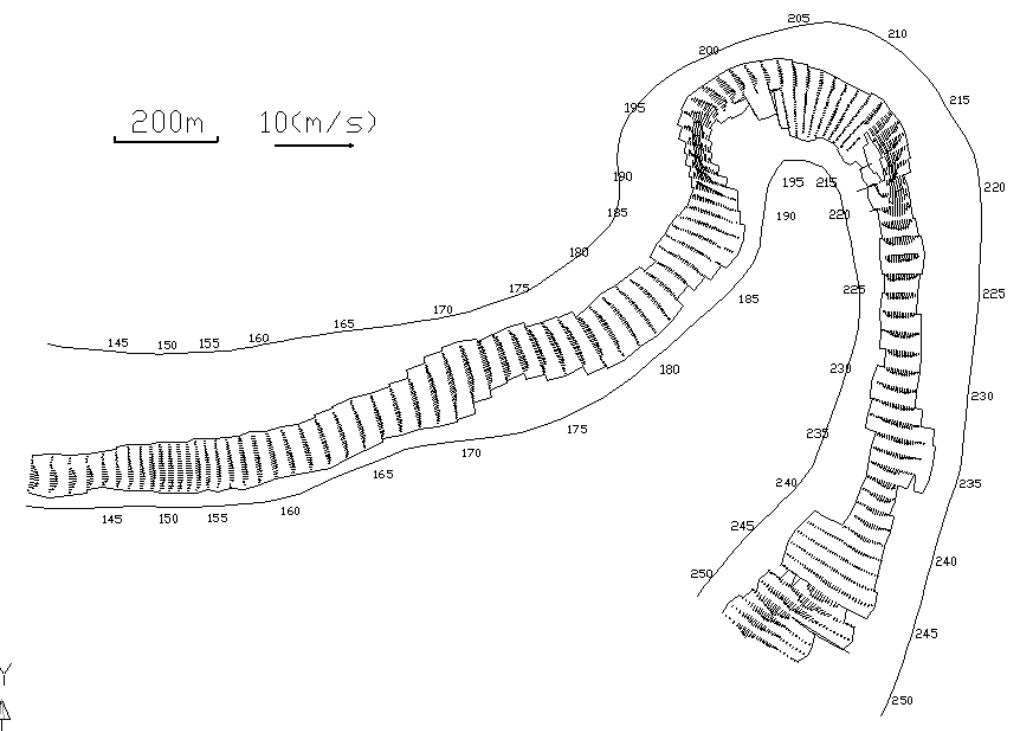

Figure 4. Flow Field under $74 \mathrm{~m} 3 / \mathrm{s}$ with the Regulation Works 


\section{Conclusions}

According to the riverbed morphological characteristics of the reach, the depth-averaged twodimensional mathematical model is established under the orthogonal curvilinear body-fitted coordinate system with staggered grid. According to characteristics of riverbed evolution and navigation obstructions, the regulation methods are adopted. On the basis of the above-mentioned methods, variations of water level, surface slope and flow velocity, caused by the regulation works in fluctuating backwater zone of Ankang Hydro-junction are analyzed. And finally, the reasonable regulation works are proposed to meet the design waterway dimension.

\section{Acknowledgements}

This work was financially supported by National High Technology Research and Development Program 863 (2012AA112508), National Natural Science Foundation of China (51209112), and Basic research funding of national commonweal research institutions (TKS130202).

\section{References}

[1] Cheng WH, Wang CH (1988). Calculation of River Course Flow Velocity Field with the Orthogonal Curvilinear Grid and "Freeze" Methods. Journal of Hydraulic Engineering Water, (6):18-25.

[2] Dou GR, Zhao SQ, Huang YF (1987). Research on River Course Two-dimensional All-sand Mathematical Model. Scientific Research on Water Conservancy and Transportation, (2):1-12.

[3] Liu WL (2003). Two-dimensional Plane All-sand Mathematical Model Research and Its Application in Waterway Engineering. Wuhan University.

[4] Liu WL (2005). Analysis Report on Alluvial Process of Fluctuating Backwater Zone of Ankang Reservoir. Tianjin Research Institute for Water Transport Engineering. M.O.T.

[5] Liu WL (2004). Two-dimensional Plane All-sand Numerical Simulation Method and the Application, Journal of Wuhan University, 37(6):27-31.

[6] Li YT, Xie JH (1986). Numerical Simulation of Alluvial Plain River Surface Flow. Journal of Hydraulic Engineering Water, (11):9-15.

[7] Pan QS et al (1999). Research on Sediment Problems of Three Gorges Project. China Water Resources and Electric Power Press, 71-105.

[8] S. V., Patankar (1980). Numerical Heat Transfer and Fluid Flow. Hemisphere Pub. Co., Washington, D. C.

[9] Xie JH (1998). River Simulation. Wuhan Institute of Hydraulic and Electric Engineering.

[10]Zhang RJ, Xie JH et al (1989). River Sediment Dynamics. Water Resources and Electric Power Press.

[11]Zhao LB (2005). Analysis Report on Natural Characteristics and Navigation Conditions of the Fluctuating Backwater Zone of Ankang Reservoir. Tianjin Research Institute for Water Transport Engineering. M.O.T. 